\title{
Correction to: Factors associated with hospital and intensive care admission in paediatric SARS-CoV-2 infection: a prospective nationwide observational cohort study
}

\author{
Anita Uka ${ }^{1,2} \cdot$ Michael Buettcher $^{3} \cdot$ Sara Bernhard-Stirnemann ${ }^{4} \cdot$ Yves Fougère $^{5} \cdot$ Dehlia Moussaoui $^{6} \cdot$ Lisa Kottanattu $^{7}$. \\ Noémie Wagner ${ }^{6} \cdot$ Petra Zimmermann ${ }^{1,2,8} \cdot$ Nicole Ritz ${ }^{9,10,11}$. Swiss Paediatric Surveillance Unit (SPSU)
}

Published online: 15 January 2022

(c) The Author(s) 2022

\section{Correction to: European Journal of Pediatrics} https://doi.org/10.1007/s00431-021-04276-9

In the published version of the above article, the Swiss Paediatric Surveillance Unit (SPSU) representatives were missing. The names have been added.

The original article has been corrected.

Publisher's Note Springer Nature remains neutral with regard to jurisdictional claims in published maps and institutional affiliations.

The original article can be found online at https://doi.org/10.1007/ s00431-021-04276-9.

Nicole Ritz

Nicole.ritz@unibas.ch

Anita Uka

anita.uka@unifr.ch

Michael Buettcher

michael.buettcher@luks.ch

Sara Bernhard-Stirnemann

sara.bernhard@ksa.ch

Yves Fougère

yves.fougere@chuv.ch

Dehlia Moussaoui

Dehlia.Moussaoui@hcuge.ch

Lisa Kottanattu

Lisa.Kottanattu@eoc.ch

Noémie Wagner

Noemie.Wagner@hcuge.ch

Petra Zimmermann

petra.zimmermann@unifr.ch

Swiss Paediatric Surveillance Unit (SPSU)

spsu@bag.admin.ch

1 Faculty of Science and Medicine, University of Fribourg, Fribourg, Switzerland
2 Department of Paediatrics, Fribourg Hospital HFR, Fribourg, Switzerland

3 Paediatric Infectious Diseases, Children's Hospital Lucerne, Luzern, Switzerland

4 Department of Paediatrics, Children's Hospital, Cantonal Hospital Aarau, Aarau, Switzerland

5 Pediatric Infectious Diseases and Vaccinology Unit, Department Women-Mother-Child, Lausanne University, Hospital, Lausanne, Switzerland

6 Department of PaediatricsGynaecology and Obstetrics, General Paediatrics Division, Geneva University Hospitals, Geneva, Switzerland

7 Ente Ospedaliero Cantonale, Istituto Pediatrico Della Svizzera Italiana, Bellinzona, Switzerland

8 Infectious Diseases Research Group, Murdoch Children's Research Institute, Parkville, Australia

9 Paediatric Infectious Diseases and Vaccinology, University of Basel Children's Hospital, Basel, Switzerland

10 Department of Paediatrics, The Royal Children's Hospital Melbourne, The University of Melbourne, Melbourne, Australia

11 University Children's Hospital Basel UKBB, Spitalstrasse 33, CH-4031 Basel, Switzerland 